\title{
Mortality in patients with loss of consciousness at the scene of trauma
}

\author{
André Luciano Baitello • Francisco de Assis Cury • \\ Paulo César Espada $\cdot$ Rogério Yukio Morioka . \\ José Maria Pereira de Godoy
}

Received: 19 July 2009 / Accepted: 8 December 2009 /Published online: 9 February 2010

(C) Springer-Verlag London Ltd 2010

\begin{abstract}
Background and aim: The aim of this study was to evaluate if loss of consciousness at the scene of an accident in patients with thoracic trauma classified by the Abbreviated Injury Scale (AIS) as thorax $>2$ has a different outcome in respect to immediate hospital discharge, hospitalization, death and type of accident.

Methods: A prospective study was performed in the Regional Trauma Center of São José do Rio Preto. All patients with scores related to thoracic injury $\geq 2$ were included in this study. Thus, 134 patients with penetrating and 231 with blunt thoracic injuries were evaluated. The chi-square, Fisher's exact and relative risk tests were utilized for statistical analysis with an alpha error greater than $5 \%(\mathrm{p}<0.05)$ being considered statistically significant. Results: A significantly higher number of patients who lost consciousness (35-33.9\%) died compared to those who did not lose consciousness (9-3.5\%, Fisher's exact test: $\mathrm{p}<$ 0.0001 ) where the relative risk (RR) of death when an individual lost consciousness was 9.7 (95\% CI: 4.8-19.4). In respect to the necessity of hospital treatment, those who lost consciousness were more commonly hospitalized (Fisher's exact test: $\mathrm{p}<0.0001$ ).
\end{abstract}

\footnotetext{
A. L. Baitello · F. de Assis Cury • P. C. Espada - R. Y. Morioka Department of Trauma,

Medical School of São José do Rio Preto, FAMERP,

São Paulo, Brazil

J. M. P. de Godoy $(\bowtie)$

Cardiology and Cardiovascular Surgery Department,

Medical School of São José do Rio Preto-FAMERP,

Rua Floriano Peixoto, 2950,

São José do Rio Preto, SP 15020-010, Brazil

e-mail: godoyjmp@riopreto.com.br
}

Conclusion: The loss of consciousness at the time of trauma is a warning sign in patients with thoracic injuries whether associated with other types of injuries or not.

Keywords Loss of consciousness - Thoracic trauma . Mortality

\section{Introduction}

The incidence of thoracic injuries in the USA is 12 per 1 million inhabitants per day, with 20 to $25 \%$ of the deaths resulting from trauma attributed to thoracic injuries. It is estimated that thoracic injuries account for approximately 16,000 deaths in the USA annually [1-4].

The lungs, rib, stern, scapula, diaphragm, heart and aorta are the most important regions of injury in thorax trauma [5-7].

Chest $\mathrm{x}$-ray is the initial primary imaging examination for the evaluation of the thorax in polytrauma patients, enabling an assessment of the extent of injuries and early screening for management decisions [8].

The Abbreviated Injury Scale (AIS) and the Injury Severity Score (ISS), which are accurate methods to assess the severity of injuries and have many potential applications, have been introduced in emergency medicine [9]. The AIS is a consensus-derived, anatomically based system of grading injuries on a non-linear scale ranging from 1 (minor injury) to 6 (lethal injury) [10,11].

Loss of memory is most commonly reported with brain trauma $[12,13]$; however, the association between loss of memory at the time of the initial treatment and the evolution of these patients has not been stressed in the 
Table 1 Loss of consciousness and evolution of the patients in respect to the outcome (immediate hospital discharge, hospitalization and death)

\begin{tabular}{lllll}
\hline & Immediate discharge & Hospitalization & Death & Total \\
\hline No & 113 & 135 & 9 & 257 \\
Yes & 13 & 55 & 35 & 103 \\
Total & 126 & 190 & 44 & 360 \\
\hline
\end{tabular}

Chi-square $=76.542 ; \mathrm{DF}=2 ; \mathrm{p}=0.000$

literature. The aim of this study was to evaluate whether loss of consciousness at the scene of an accident in patients with thoracic injuries classified as $\geq 2$ according to the AIS has a different outcome compared to less severe injuries in respect to immediate hospital discharge, hospitalization, death and type of accident.

\section{Methods}

A prospective study was carried out at the Regional Trauma Center of São José do Rio Preto from 1 July 2004 to 30 June 2005 to identify patients with thoracic injuries according to the AIS. All patients with scores $\geq 2$ were included in the study. The AIS is a consensus-derived, anatomically based system of grading injuries on a nonlinear scale ranging from 1 (minor injury) to 6 (lethal injury) $[10,11]$. Loss of consciousness at the scene of the accident before evaluation in the hospital emergency room was correlated with: immediate hospital discharge, hospitalization and death. The evaluation of the loss of consciousness was made by trained emergency ambulance teams, specialists in this type of situation. Additionally, associations between the types of trauma and loss of consciousness were evaluated in respect to (1) car crashes, (2) motorbike crashes, (3) pedestrian-vehicle collisions, (4) falls, (5) bicycle accidents, (6) gunshot wounds, (7) stabbings, (8) fights, (9) burns, (10) impaling, (11) electric shock involving falls to the ground, (12) bites, (13) drowning with thoracic trauma, (14) suicide, (15) nonintentional injuries and (16) others. The injuries were evaluated using the ISS, TRISS and the Revised Trauma Score (RTS), but this was not the objective of the study.

The chi-square, Fisher's exact and relative risk tests were utilized for statistical analysis with an alpha error greater than $5 \%(\mathrm{p}<0.05)$ considered statistically significant.

\section{Results}

A total of 365 patients classified with scores of $\geq 2$ according to the AIS were evaluated. The ages of the patients varied from 13 to 89 years old (mean, 37.9 years). The number of men (291) was significantly greater than the number of women $(74)(p<0.0001)$. A total of 134 patients with penetrating thoracic injuries and 231 with blunt injuries were included in this study.

A significantly higher number of patients who lost consciousness (35-33.9\%) died compared to those who did not lose consciousness (9-3.5\%, Fisher's exact test: $\mathrm{p}<$ 0.0001 ) where the relative risk (RR) of death when an individual lost consciousness was 9.7 (95\% CI: 4.8-19.4). In respect to discharge from hospital, patients who lost consciousness were more commonly hospitalized (Fisher's exact test: $\mathrm{p}<0.0001$ ).

Forty-seven patients arrived at the hospital with a systemic arterial pressure of $0 \mathrm{mmHg}$ and 45 patients with a pressure of less than $90 \mathrm{mmHg}$. In relation to the respiration rate, 49 patients had a rate of 0 inspirations per minute and 8 patients less than 10 inspirations per minute.
Table 2 Types of trauma associated with loss of consciousness

Others: burns, impaling, electric shock, bites, drowning, suicide and non-intentional wounds

\begin{tabular}{llllll}
\hline Type of accident & $\begin{array}{l}\text { Loss of } \\
\text { consciousness }\end{array}$ & $\begin{array}{l}\text { Without loss } \\
\text { of consciousness }\end{array}$ & Total & p-value & $\begin{array}{l}\text { Relative risk } \\
95 \% \text { CI }\end{array}$ \\
\hline Car crash & 35 & 54 & 89 & 0.001 & 1.5 (1.1 to 2.1) \\
Motor crash & 12 & 33 & 45 & 0.9143 & 0.9 (0.5 to 1.5) \\
Pedestrian-vehicle collisions & 13 & 8 & 21 & 0.0017 & 2.3 (1.5 to 3.4) \\
Falls & 19 & 54 & 73 & 0.3964 & 0.8 (0.5 to 1.3) \\
Bicycle accidents & 9 & 13 & 22 & 0.2233 & 1.4 (0.8 to 2.5) \\
Gunshots & 6 & 12 & 18 & 0.6039 & $1.1(0.5$ to 2.3) \\
Stabbings & 2 & 38 & 40 & 0.0001 & $0.1(0.04$ to 0.6) \\
Fights & 2 & 11 & 13 & 0.762 & 0.3 (0.08 to 1.2) \\
Others & 2 & 11 & 13 & 0.3635 & $0.5(0.1$ to 1.9) \\
Total 103 & 257 & 360 & & & \\
\hline
\end{tabular}


Table 3 Medians of RTS for the different types of injury

\begin{tabular}{lllll}
\hline Trauma** & $\mathrm{N}<$ & $\mathrm{N} \geq$ & Median & $\mathrm{Q} 3-\mathrm{Q} 1$ \\
\hline 1 & 21 & 70 & 7.84 & 0.00 \\
$10,11,14$ & 0 & 13 & 7.84 & 0.00 \\
15 & 0 & 17 & 7.84 & 0.00 \\
2 & 10 & 36 & 7.84 & 0.00 \\
3 & 10 & 12 & 7.84 & 2.96 \\
4 & 8 & 68 & 7.84 & 0.00 \\
5 & 4 & 18 & 7.84 & 0.00 \\
6 & 10 & 8 & 6.74 & $7.84 *$ \\
7 & 7 & 34 & 7.84 & 0.00 \\
8 & 1 & 23 & 7.84 & 0.00 \\
\hline
\end{tabular}

*Chi-square

**Injury: (1) car crash, (2) motorbike crash, (3) pedestrian-vehicle collisions, (4) falls, (5) bicycle accidents, (6) gunshots, (7) stabbings, (8) fights, (9) burns involving falls, (10) impaled, (11) electric shock with fall, (12) bites, (13) drowning after head/thoracic injury, (14) suicide, (15) non-intentional wounds

Ten patients with head injuries had AIS of 6,50 patients had AIS of 5, and 115 patients had AIS of 4 .

The types of accident most associated with loss of consciousness were car crashes and pedestrian-vehicle collisions; stabbings were not associated with loss of consciousness (Tables 1, 2). There was no statistical significance comparing the other types of accidents. Tables 3, 4 and 5 show the results of the trauma indexes. The RTS (Table 3), TRISS (Table 4) and ISS (Table 5)

Table 4 Medians of TRISS for the different types of injury

\begin{tabular}{lllll}
\hline Trauma** & $\mathrm{N}<$ & $\mathrm{N} \geq$ & Median & $\mathrm{Q} 3-\mathrm{Q} 1$ \\
\hline 1 & 51 & 40 & 98.9 & 5.5 \\
$10,11,14$ & 4 & 9 & 99.3 & 0.8 \\
15 & 3 & 14 & 99.6 & 0.2 \\
2 & 18 & 28 & 99.4 & 0.8 \\
3 & 18 & 4 & 95.5 & $36.8^{*}$ \\
4 & 41 & 35 & 98.8 & 3.6 \\
5 & 11 & 11 & 99.2 & 3.3 \\
6 & 16 & 2 & 96.9 & 53.9 \\
7 & 25 & 16 & 99.1 & 1.0 \\
8 & 6 & 18 & 99.4 & 1.4 \\
\hline
\end{tabular}

\section{${ }^{*}$ Chi-square}

**Injury: (1) car crash, (2) motorbike crash, (3) pedestrian-vehicle collisions, (4) falls, (5) bicycle accidents, (6) gunshots, (7) stabbings, (8) fights, (9) burns involving falls, (10) impaled, (11) electric shock with fall, (12) bites, (13) drowning after head/thoracic injury, (14) suicide, (15) non-intentional wounds
Table 5 Medians of ISS for the different types of injury

\begin{tabular}{lllll}
\hline Trauma** & $\mathrm{N}<$ & $\mathrm{N} \geq$ & Median & $\mathrm{Q3}-\mathrm{Q} 1$ \\
\hline 1 & 38 & 53 & 13.0 & 18.0 \\
$10,11,14$ & 7 & 6 & 10.0 & 9.5 \\
15 & 14 & 3 & 5.0 & 4.0 \\
2 & 26 & 20 & 9.0 & 11.0 \\
3 & 6 & 16 & 16.0 & 18.5 \\
4 & 50 & 26 & 8.0 & 12.0 \\
5 & 11 & 11 & 10.0 & 9.5 \\
6 & 3 & 15 & 22.5 & 19.8 \\
7 & 20 & 21 & 13.0 & 9.0 \\
8 & 17 & 7 & 6.0 & 7.5 \\
\hline
\end{tabular}

*Chi-square

**Injury: (1) car crash, (2) motorbike crash, (3) pedestrian-vehicle collisions, (4) falls, (5) bicycle accidents, (6) gunshots, (7) stabbings, (8) fights, (9) burns involving falls, (10) impaled, (11) electric shock with fall, (12) bites, (13) drowning after head/thoracic injury, (14) suicide, (15) non-intentional wounds

demonstrated that there were significant differences in the medians of the different types of trauma (Mood's median test: $\mathrm{p}=0.000$ ). Additionally, significant differences were observed in the association between the type of injury and the respiratory rate (Mood's median test: $p=$ 0.04, Table 6).

The mean systolic pressure was significantly lower in patients with gunshot wounds $(p<0.0001$, Table 7 ).

Table 6 The association between the type of injury and the respiratory rate

\begin{tabular}{lllll}
\hline Trauma** & $\mathrm{N}<$ & $\mathrm{N} \geq$ & Median & Q3-Q1 \\
\hline 1 & 40 & 51 & 20.0 & 4.0 \\
$10,11,14$ & 6 & 7 & 20.2 & 5.5 \\
15 & 9 & 8 & 19.0 & $4.5^{*}$ \\
2 & 18 & 28 & 20.0 & 3.5 \\
3 & 6 & 16 & 20.0 & 5.0 \\
4 & 29 & 47 & 20.0 & 2.0 \\
5 & 6 & 16 & 20.0 & 2.3 \\
6 & 8 & 10 & 20.0 & 22.0 \\
7 & 5 & 36 & 20.0 & 3.5 \\
8 & 9 & 15 & 20.0 & 2.0 \\
\hline
\end{tabular}

\section{*Chi-square}

**Injury: (1) car crash, (2) motorbike crash, (3) pedestrian-vehicle collisions, (4) falls, (5) bicycle accidents, (6) gunshots, (7) stabbings, (8) fights, (9) burns involving falls, (10) impaled, (11) electric shock with fall, (12) bites, (13) drowning after head/thoracic injury, (14) suicide, (15) non-intentional wounds 
Table 7 Mean systolic blood pressure and standard deviation in the different types of injuries

*ANOVA: $p=0.000$

\begin{tabular}{llll}
\hline Type of injury & Patients & Mean & Standard deviation \\
\hline Car crash & 91 & 117.58 & 40.92 \\
Motorbike crash & 46 & 114.57 & 36.62 \\
Pedestrian-vehicle collisions & 22 & 112.73 & 57.91 \\
Falls & 76 & 125.00 & 34.89 \\
Bicycle accidents & 22 & 122.73 & 37.44 \\
Gunshots & 18 & 75.00 & $60.32 *$ \\
Stabbings & 41 & 118.54 & 33.36 \\
Fights & 24 & 131.25 & 19.63 \\
Non-intentional wounds & 13 & 125.82 & 13.19 \\
Impaling, electric shock, suicide & 17 & 125.38 & 12.66 \\
\hline
\end{tabular}

There were no significant differences between blunt and penetrating traumas in respect to discharge after the initial evaluation, hospitalization and death (chi-square test: $p=$ 0.3 , Table 8). Moreover, there were no significant differences between blunt and penetrating injuries in respect to the trauma indexes, blood pressure, pulse and respiration rate.

\section{Discussion}

This study shows that loss of consciousness is a risk factor that affects the prognosis of patients that suffer thoracic injuries whether associated with other types of injury or not. Patients who lost consciousness were more frequently hospitalized and died in the hospital, thereby demonstrating the greater severity of the clinical status with a relative risk of 9.7. In this study, the evaluation of the loss of consciousness was made between the scene of the accident and the patient's arrival in the emergency room, and so this is simple and rapid information that may be used as a warning sign for prognosis. These observations associating thoracic injury with loss of consciousness were not found in publications linked to PubMed, Scopus, ISI, ATLS (Advanced Trauma Life Support) and Scielo, and so provide

Table 8 Blunt and penetrating traumas in respect to outcome (discharge after the initial evaluation, hospitalization and death)

\begin{tabular}{lllll}
\hline & Quick discharge & Hospitalization & Death & Total \\
\hline Penetrating & 42 & 79 & 13 & 134 \\
Blunt & 84 & 118 & 30 & 232 \\
Total & 126 & 197 & 43 & 366 \\
\hline
\end{tabular}

Chi-square test: $\mathrm{p}=0.306$ new information for the thoracic surgeon in respect to the severity of wounds.

In this study, 47 patients arrived at the hospital with blood pressure that was unrecordable, which affected the state of consciousness of these patients. Brain injuries were another important aspect in this study; 175 patients had an AIS $\geq 4$. Thus, the severity of this type of injury may contribute to the percentage of patients who lose consciousness. The pre-hospital triage policy might have impacted the outcome as the ambulance service transports the more severely ill patients directly to a trauma reference center and the less severely ill patients to other smaller centers. Although this was not an objective of the current study, the time from the ambulance service arriving at the scene of the accident to the patient arriving at hospital was quick and similar for all patients. This policy may contribute to the access of more severely ill patients, those who probably would have died if the ambulance service was not specialized, to specialized treatment.

Thoracic injury is a significant cause of mortality, and identification of factors involved in the trauma are important [14]. In the current study, loss of consciousness was identified as yet another aggravating factor in thoracic injuries. The type of accident influenced the outcomes in this study; loss of consciousness is associated with car crashes and pedestrian-vehicle collisions; however, stab wounds are not associated with loss of consciousness.

\section{Conclusion}

Loss of consciousness evaluated at the time of the injury is a warning sign about the severity of thoracic injuries of patients whether associated with other types of injuries or not. 


\section{References}

1. Anthoine D, Vaillant G, Martinet Y (1990) Diagnostic pitfalls, artifacts and difficulties of thoracic radiography. Rev Pneumol Clin 46(6):251-259

2. Collins J (2000) Chest wall trauma. J Thorac Imaging 15(2):112119

3. Fabian TC, Croce MA, Minard G (2002) Current issues in trauma. Curr Probl Surg 39(12):1160-1244

4. Reuter M (1996) Trauma of the chest. Eur Radiol 6(5):707-716

5. Miller DL, Mansour KA (2007) Blunt traumatic lung injuries. Thorac Surg Clin 17(1):57-61, vi

6. Sangster GP, González-Beicos A, Carbo AI, Heldmann MG, Ibrahim H, Carrascosa P, Nazar M, D'Agostino HB (2007) Blunt traumatic injuries of the lung parenchyma, pleura, thoracic wall, and intrathoracic airways: multidetector computer tomography imaging findings. Emerg Radiol 14(5):297-310

7. Waydhas C, Nast-Kolb D (2006) Chest injury. Part II: Management of specific injuries. Unfallchirurg 109(10):881-892, quiz $893-4$
8. Ho ML, Gutierrez FR (2009) Chest radiography in thoracic polytrauma. AJR Am J Roentgenol 192(3):599-612

9. Ndiaye A, Chambost M, Chiron M (2009) The fatal injuries of car drivers. Forensic Sci Int 30;184(1-3):21-27

10. Kilgo PD, Meredith JW, Osler TM (2006) Incorporating recent advances to make the TRISS approach universally available. J Trauma 60(5):1002-1008, discussion 1008-1009

11. Ott R, Krämer R, Martus P, Bussenius-Kammerer M, Carbon R, Rupprecht H (2000) Prognostic value of trauma scores in pediatric patients with multiple injuries. J Trauma 49(4):729-736

12. Willemse-van Son AH, Ribbers GM, Verhagen AP, Stam HJ (2007) Prognostic factors of long-term functioning and productivity after traumatic brain injury: a systematic review of prospective cohort studies. Clin Rehabil 21(11):1024-1037, Review

13. Klein E, Caspi Y, Gil S (2003) The relation between memory of the traumatic event and PTSD: evidence from studies of traumatic brain injury. Can J Psychiatry 48(1):28-33

14. Cury F, Baitello SL, Echeverria RF, Espada P, Godoy JMP (2009) Rates of thoracic trauma and mortality due to accidents in Brazil. Annais of Thorax Medicine 4(1):25-26 